\title{
Management of depression in elderly stroke patients
}

This article was published in the following Dove Press journal:

Neuropsychiatric Disease and Treatment

24 August 2010

Number of times this article has been viewed

Johan Lökk'

Ahmad Delbari ${ }^{1,2}$

'Department of Neurobiology, Care Sciences and Society, Karolinska Institute, Stockholm, Sweden ${ }^{2}$ Iranian Research Center on Aging, University of Social Welfare and Rehabilitation, Tehran, Iran
Correspondence: Johan Lökk R94, Karolinska University Hospital, Huddinge, SE-14186 Stockholm, Sweden Tel +4-685-858-0000

Fax +4-685-858-5482

Email johan.lokk@karolinska.se
Abstract: Poststroke depression (PSD) in elderly patients has been considered the most common neuropsychiatric consequence of stroke up to 6-24 months after stroke onset. When depression appears within days after stroke onset, it is likely to remit, whereas depression at 3 months is likely to be sustained for 1 year. One of the major problems posed by elderly stroke patients is how to identify and optimally manage PSD. This review provides insight to identification and management of depression in elderly stroke patients. Depression following stroke is less likely to include dysphoria and more likely characterized by vegetative signs and symptoms compared with other forms of late-life depression, and clinicians should rely more on nonsomatic symptoms rather than somatic symptoms. Evaluation and diagnosis of depression among elderly stroke patients are more complex due to vague symptoms of depression, overlapping signs and symptoms of stroke and depression, lack of properly trained health care personnel, and insufficient assessment tools for proper diagnosis. Major goals of treatment are to reduce depressive symptoms, improve mood and quality of life, and reduce the risk of medical complications including relapse. Antidepressants (ADs) are generally not indicated in mild forms because the balance of benefit and risk is not satisfactory in elderly stroke patients. Selective serotonin reuptake inhibitors are the first choice of PSD treatment in elderly patients due to their lower potential for drug interaction and side effects, which are more common with tricyclic ADs. Recently, stimulant medications have emerged as promising new therapeutic interventions for PSD and are now the subject of rigorous clinical trials. Cognitive behavioral therapy can also be useful, and electroconvulsive therapy is available for patients with severe refractory PSD.

Keywords: depression, poststroke, stroke

\section{Scope of the problem: aging, stroke, and poststroke depression}

Incidence of stroke increases sharply with age, ${ }^{1}$ a fact that each successive decade above 55 years leads to a doubling of stroke incidence. ${ }^{2}$ According to a recent populationbased stroke study in Europe, $70.2 \%$ of stroke patients were older than 65 years, and the median age was 73 years (interquartile range, $62-81$ ). ${ }^{3}$ The combined impact of increased life expectancy and medical management advancements has resulted in a larger number of elderly persons surviving stroke. ${ }^{4}$

The physical and psychological sequelae caused by stroke can be devastating. ${ }^{5}$ Poststroke depression (PSD) is one of the unresolved issues in recovery and rehabilitation of the stroke patients. It has been considered the most common neuropsychiatric consequence of stroke. ${ }^{6}$ Depression may either directly or indirectly lead to more significant impairments in daily activities, which require more careful services and 
institutionalization of stroke patients. $^{7-9}$ The risk of fatality is higher in stroke patients with depression compared with nondepressed stroke patients. ${ }^{10}$ Deteriorated cognitive function and increased medical complication rates among patients with PSD adversely influence the speed of recovery and the level of residual function following rehabilitation. ${ }^{11-12}$ Other consequences of PSD include higher health care costs, diminished social abilities, and an increased risk of vascular-related events and death. ${ }^{13,14}$

One of the major problems posed by elderly stroke patients is how to identify and optimally manage PSD, which is more common in elderly stroke patients than younger stroke patients. The aim of this review is to provide insight to symptoms, identification, diagnosis, and management of depression in elderly stroke patients.

\section{Search strategy and selection criteria}

References for this review were recognized through search in PubMed for potentially relevant articles with the search terms of "depression" and "depressive disorder" in combination with "elderly," "older," "stroke," "cerebrovascular," and "ischemia." Preference was given to articles published between January 1981 and January 2010. Only articles published in English were reviewed. The final citation list was selected based on relevance to PSD in elderly patients. Our search strategy identified 2,547 nonduplicated references of which 274 articles were considered relevant. After reviewing abstracts, 150 articles were examined in detail, yielding 67 articles to match the eligibility criteria.

\section{Epidemiology of PSD}

Depression is a common consequence of stroke up to 2-3 years after stroke onset. ${ }^{15}$ Prevalence rates of PSD vary from $6 \%$ to $79 \% .^{16,17}$ These rates show considerable variation between studies and amongst different populations. PSD rates depend on the setting in which patients are examined, demonstrating greater rates among hospital inpatient-based locations (acute stroke units, general hospital wards, or rehabilitation centers) than community-based settings. ${ }^{5,18}$ Differences in definitions of PSD and patient selection criteria (including prior patient history of depression) combined with disparity among evaluation instruments resulted in large variability between studies, making results difficult to interpret. ${ }^{17,19}$ In the acute period ( $<1$ month after stroke), the frequency of depressive disorders was found to be $30 \%$, $33 \%$, and $36 \%$ in rehabilitation, community, and hospitalbased settings, respectively. ${ }^{20}$ Approximately $1-6$ months after stroke, the frequency of depressive disorders was somewhat higher in rehabilitation settings (36\%) compared with community- and hospital-based settings. ${ }^{20}$ Most studies examined the risk of depression in younger patient populations, whereas only few studies investigated that in elderly stroke patients. Few studies relate the frequency of PSD adjusted for age or sex. ${ }^{21,22}$ The prevalence of depressive disorders in those older than 55 years (when stroke commonly occurs) has been estimated to be $18 \%$ in women and $11 \%$ in men. ${ }^{23}$ Even this figure may be an underestimation due to exclusion of patients with impaired communication, such as patients with aphasia (including $25 \%$ of the stroke patients) or patients with dementia. ${ }^{24}$ Among a population of elderly residents in the United States, a community survey on the prevalence of depression showed $42.9 \%$ for men and $64.1 \%$ for women, generally a high rate of stroke survivors. ${ }^{25}$ Linden et $\mathrm{al}^{26}$ showed that the frequency of depressive disorders in a consecutive series of hospitalized elderly stroke patients 20 months after stroke onset was 34\% in the stroke patients and $13 \%$ in controls. Patients recruited for this study were selected from hospitalized stroke patients, who were more severely affected in general. Because most stroke patients in Sweden are treated in hospitals (even those with mild symptoms), the authors considered that their sample reasonably reflects the total elderly stroke population. ${ }^{26}$

\section{Pathophysiology of PSD}

The primary biological mechanism is proposed to be the cause of PSD, whereby ischemic insults directly affect neural circuits involved in mood regulation. ${ }^{27,28}$ An injury to the brain's catecholamine pathway reduces the release of neurotransmitters with a likely depression as a result. A depletion in cortical biogenic amines is found after a disruption of frontal-subcortical circuits after stroke. ${ }^{29}$ However, there are also arguments for a psychological basis of PSD put forth by researchers. This relates to the similarity of symptoms and treatment response profiles between PSD and functional depression. Carson et $\mathrm{al}^{30}$ performed a meta-analysis in which they noted that the risk of depression did not relate to the location of the cerebral lesion. However, most PSD appears to be multifactorial in origin. However, some stroke survivors may have a PSD purely biological in origin, and some purely psychological.

\section{Clinical manifestations of PSD}

PSD occurring within the first 3 months of stroke is classified as "early" and is defined as "late" when the symptoms appear later. ${ }^{31}$ Early PSD patients have more depressive somatic 
signs compared with psychological symptoms $\mathrm{s}^{32}$ and more frequently show early symptoms of melancholy, vegetative signs, and psychological disturbances. ${ }^{33}$ PSD may appear shortly after stroke but usually develops several months after a cerebrovascular event. ${ }^{18}$ Peak incidence and greatest severity of depression commonly occur between 6 months and 2 years after stroke. ${ }^{34}$ Robinson et $a{ }^{34}$ found major depression in assessments immediately after a stroke in almost one-third of patients and noted that $60 \%$ of those patients still were depressed 1 year later. Depressive symptoms at any level of severity can be recognized in $18 \%-30 \%$ of patients during $3-5$ years after stroke. ${ }^{35-37}$

Depression presents differently among patients with neurological syndromes. ${ }^{24}$ Depression following stroke, especially stroke with right hemisphere damage, is less likely to include dysphoria and more likely characterized by vegetative signs and symptoms compared with other forms of late-life depression. ${ }^{38}$ In 2004, Mast ${ }^{39}$ showed that stroke patients were more likely to exhibit social withdrawal and were less likely to exhibit agitation compared with geriatric depression accompanying other medical illnesses, although there were no differences in depressed mood or energy between them. Robinson and his coworkers ${ }^{40,41}$ suggested that somatic symptoms are more common among stroke patients when depressed mood is present. In this case, clinicians are more sensitive to similarities between somatic features, commonly seen in older medical patients, and clinical features typical of depression. ${ }^{42}$ For the most accurate diagnoses, clinicians should rely more on nonsomatic symptoms rather than somatic symptoms. ${ }^{43}$ Some symptoms are common to both stroke and depression, such as sleep disturbances, concentration difficulties, and reduced appetite, which might cause an overestimation of depression in stroke patients. ${ }^{44} \mathrm{In}$ older people with cognitive impairments due to aging and degenerative disorders, additional cognitive impairments caused by depression can be more troublesome. ${ }^{45}$ About $2 \%-3 \%$ of patients without stroke show "masked" depression (depressive symptoms without an associated depressed mood) with manifestations of biological rhythm impairment (like sleeplessness or hypersomnia) and somatization, particularly autonomic vascular dystonia, vertigo, or various dysalgic phenomena. ${ }^{46}$

\section{Depressive disorders in older vs younger adults}

Clinically, there are differences between depressed younger and older people. When comparing elderly adult depression vs young adult depression, there is a dynamic increase in the level of somatic symptoms, including loss or lack of interests and other affective symptoms, such as dysphoria, worthlessness, or guilt. ${ }^{24}$ Somatic symptoms often obscure depression in older people either because of the somatic nature of the disorder or because of the escalation of symptoms of an existing physical illness ${ }^{47}$ (Table 1). Older patients seldom have evident signs of low mood, so they do not meet the Diagnostic and Statistical Manual of Mental Disorders, Fourth Edition, (DSM-IV) criteria for major depression. ${ }^{47}$ It has been shown that older adults focus more on positive and emotionally meaningful experiences, which provides better emotion regulation with advancing age. ${ }^{48}$ In contrast to younger depressed patients, elderly patients often hide their mood with the mentality that decreased life fulfillment is a normal consequence of aging and disease (stroke). ${ }^{49}$ Among depressed older adults, subjective complaints of poor memory and lack of concentration are common, whereas symptoms of fatigue, sleep disturbance, psychomotor retardation, and hopelessness about the future are more common among depressed younger adults. ${ }^{50}$

\section{Factors contributing to the risk of PSD}

Several factors that impact the risk of PSD development have been identified. Social isolation, living alone, physical functional impairments, or a history of depression (or other psychiatric disorder) are identified as predictive risk factors for PSD. ${ }^{51-53}$ However, not all studies confirm the association between PSD and social factors, such as poststroke social isolation and living alone. ${ }^{53}$ Some symptoms associated with PSD are the same as the risk factors, such as reduced social activity, failure to return to work, and poor participation in processes of rehabilitation. ${ }^{54}$

Gender has been found to be mildly associated with PSD. Some authors have reported that PSD is twice as common in women as in men, ${ }^{55}$ whereas others found that older, physically disabled men with inadequate social support

Table I Differences in clinical picture between younger and elderly patients with depressive disorders ${ }^{47}$

\begin{tabular}{lll}
\hline & Younger patients & Elderly patients \\
\hline Depressed mood & ++ & $+(+)$ \\
Cognitive impairment & + & ++ \\
Retardation & ++ & ++ \\
Somatic symptoms & + & ++ \\
Anxiety & $+(+)$ & +++ \\
Psychotic symptoms & $(+)$ & ++ \\
Hypochondria & + & ++ \\
\hline
\end{tabular}

Note: + , higher scores of symbols indicate more symptoms. 
were more likely to experience PSD. ${ }^{56}$ Major depression in women has been associated with higher education level, prior psychiatric diagnoses, and cognitive impairments. ${ }^{56}$ Women mostly have early PSD, whereas men were more likely to have late PSD. ${ }^{15}$

There is no clear relationship between the severity of stroke and the occurrence of PSD. ${ }^{57}$ Research has shown that $50 \%$ of those who have experienced a stroke 3 months ago are more plausible to be depressed yet another year. Another difference between those patients who are shown to be depressed within days after stroke is the likelihood to show remission. ${ }^{58}$ Some investigators found depression to be more likely among persons with large lesions ${ }^{59}$ and severe stroke injury scores, ${ }^{60}$ but other studies have not confirmed this. ${ }^{61}$ Questions have arisen whether the site of infarct can influence the PSD development. ${ }^{62}$ In a meta-analysis of 35 studies conducted by Carson et $\mathrm{al}^{30}$ no data conclusively supported an association between intrahemispheric location and the risk of depression. Desmond et $\mathrm{al}^{42}$ did not recognize an association between lesion location and depression in older stoke patients. However, other studies found an increased risk of PSD with left-brain lesions. ${ }^{63}$ Linden et $\mathrm{al}^{26}$ found no association between the predominant side of symptoms at the time of the stroke onset and depressive syndromes. Likewise, there is a chance that lesion location is related to depression in the acute phase of stroke. ${ }^{26}$ This inconsistency of results might be related to study design, assessors, and assessment tools for diagnosing PSD. In most studies that showed a relationship between PSD and right-hemisphere lesions, patients with left-hemisphere damage were excluded due to the language problem caused by stroke. In contrast, in studies showing a moderate relationship between left-hemisphere lesion and PSD, stroke patients with language dysfunction were not excluded.

According to a recent systematic review by Hackett and Anderson, ${ }^{64}$ some consistent identification has been positively associated with depression following stroke, such as stroke severity, physical disability, and cognitive impairment.

\section{Diagnosis of PSD}

Diagnosis of PSD in stroke survivors may be difficult due to the presence of other symptoms such as common cognitive impairments, including aphasia, agnosia, apraxia, and memory problems. ${ }^{65}$ On the other hand, many methods of diagnosing depression rely on somatic symptoms that, in turn, may complicate the diagnosis of PSD. ${ }^{46}$ In case of the presence of depression and somatic diseases, diagnosis and treatment of PSD are even more complicated and have adverse impact on the clinical presentations and prognosis of the underlying disease. ${ }^{46}$ However, evaluation of depression among elderly stroke patients is more complex due to influence of somatic conditions, such as cognitive, sensory, and language impairments. Also certain challenging factors might overlap typical symptoms of depression from normal signs of aging and stroke disease, including thoughts regarding death, reduced sleep, fatigue, and loss of libido.

In brief, following factors contribute to the difficulty of diagnosing PSD: (1) overlapping signs and symptoms of stroke and depression, which are indistinguishable to each other, to the patient and providers, (2) lack of proper training in mental health care professionals to recognize which symptoms are more related to stroke than depression, and (3) medical care providers usually have limited knowledge about the differences between depression and "typical" signs of aging and stroke. ${ }^{57}$ Therefore, clinicians should define a set of valid criteria for diagnosis of PSD. ${ }^{66}$ Some scientists believe that symptom profile of PSD is similar to that of nonstroke depression; therefore, diagnosis criteria should be the same for both, ${ }^{40}$ but it is not commonly agreed on among all clinicians and researchers. ${ }^{67}$

\section{Screening and evaluation of PSD}

Unfortunately, there are not many researches and data regarding diagnostic criteria of PSD, but 2 reports suggest that using the Geriatric Depression Scale (GDS) has been reasonable in the elderly patients. ${ }^{68}$ This 15 -item short form questionnaire has been studied widely and is validated in a number of patients, and it is easy to administer. ${ }^{69}$ The GDS is most useful in diagnosis of depression among patients who are in higher functioning levels and have mild cognitive impairment. ${ }^{70}$ Several authors have suggested that this scale instead of other scales, like the Hospital Anxiety and Depression Scale (HADS), to be most satisfactory screening instrument for PSD. ${ }^{68,71,72}$ Neurologists can easily try GDS on a wide range of patients. ${ }^{73}$ GDS has been used to identify PSD in Caucasian patients in acute inpatient and rehabilitation conditions. ${ }^{74}$ Also GDS has performed relatively well as a screening method in Caucasian patients with stroke ${ }^{72}$ (Table 2).

In a recent clinical trial, Healey et al screened 49 elderly stroke patients for depression. ${ }^{77}$ They compared 3 depression scales: Brief Assessment Schedule Depression Cards (BASDEC), the Beck Depression Inventory-Fast Screen (BDI-FS), and the HADS. They showed that BASDEC and BDI-FS have adequate internal consistency. The BASDEC compared with BDI-FS had some benefits in criterion validity in elderly stroke 
Table 2 Characteristics of Geriatric Depression Scale

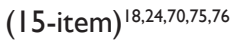

- Screening depression in elderly people

- Focus on affective rather than somatic components

- Female gender and cognitive impairment affect sensitivity

- Possible depression (cutoff $\geq 6$ )

- Clinically important depressive symptoms (cutoff $\geq 8$ )

- Self-administered test comprised yes or no questions

- Sensitivity in elderly stroke patients: $89 \%$ (cutoff 6.6)

- Specificity in elderly stroke patients: $73 \%$ (cutoff 6.6)

- Positive predictive values in elderly stroke patients: $37 \%$ (cutoff 6.6)

- Negative predictive values in elderly stroke patients: $98 \%$ (cutoff 6.6 )

patients. Regarding the criterion at the examined cutoffs, the BDI-FS and HADS were less accurate in relation. The BASDEC was developed to evaluate depression in elderly patients in a hospital ward environment. ${ }^{78}$ It is a 19 -question measure that tests depression symptoms, each question on a separate card $(8.2 \mathrm{~cm} \times 10.4 \mathrm{~cm})$, and the maximum score is 21. Higher scores of BASDEC indicate worse function. It has shown a very good sensitivity $(>0.80)$, specificity $(>0.90)$, and accuracy in predicting clinical results of medically ill elderly patients. ${ }^{79}$ Both GDS and BASDEC are not time-consuming to administer, and they are relatively free of somatic symptoms. ${ }^{80}$ Adshead et al ${ }^{78}$ showed that agreement between the 2 scales was high. However, McCrea et al ${ }^{80}$ found that BASDEC was easier to administer. In a systematic review, Hackett and Anderson ${ }^{64}$ recommended that the gold standard method for diagnosis PSD is using a semistructured psychiatric interview, which meets all the standards needed for a specific diagnostic criterion (such as DSM criteria or International Classification of Diseases). According to the current diagnostic criteria of DSM-IV-TR, 5 or more symptoms must be present at least over a 2-week period for receiving a major depression diagnosis ${ }^{81}$ (Table 3 ). Less severe forms of depressive disorder, which might not meet criteria for major

Table 3 Diagnostic criteria of DSM-IV 1,82

- Depressed mood most of the day

- Markedly diminished interest or pleasure most of the day, nearly every day

- Significant decrease in weight or appetite

- Insomnia or hypersomnia

- Psychomotor agitation or retardation, observable by others

- Fatigue or loss of energy

- Feeling of worthlessness or inappropriate guilt

- Diminished ability to concentrate or make decisions

- Recurring thoughts of death or suicidal thoughts or plans

Abbreviation: DSM-IV, Diagnostic and Statistical Manual of Mental Disorders, Fourth Edition. depression, have been diagnosed as either minor depression or dysthymic disorder. This diagnosis requires at least the presence of 1 major criterion symptom and a minimum of 1 and a maximum of 4 of the specific symptoms in a 2-year course of chronic depressive manifestations. ${ }^{57}$

\section{Management strategies of PSD}

There is no reason to refuse any kind of treatment to elderly patients with PSD based on age alone, as many older individuals had a high baseline life quality and expectancy for many more years. A key problem, which can be mentioned as a factor leading to undertreatment of PSD, is that both the patient and the doctor often do not accept this condition as a treatable illness. ${ }^{83} \mathrm{~A}$ more worrying problem is that when evaluating an older patient, the physician concentrates on other aspects of the patient and dismisses the depressive symptoms. Unfortunately, it has been estimated that $80 \%$ of the PSD patients might be missed by nonpsychiatric clinicians. ${ }^{84}$

Meanwhile, early diagnosis of PSD is extremely important to make an efficient treatment plan for the patient. The importance of an early recognition and diagnosis of PSD is widely agreed upon to improve functional and psychosocial outcomes. ${ }^{85}$ All treatments must be modified to individual needs based on patient's needs, including cost, accessibility, and availability of treatments. ${ }^{64}$ Effective treatment will generally include the participation of the family and other support networks. ${ }^{64}$ In all circumstances, it is recommended that the treating clinician supervise a person presenting with depression at least weekly for the first 6 weeks to evaluate mood changes, suicidal thinking, physical safety, the person's social life, and adverse effects of any drugs that have been prescribed. ${ }^{64}$

Major goals of such a treatment include reducing depressive symptoms, improving mood and quality of life, using health care resources appropriately, and reducing the risks of medical complications. ${ }^{86}$ The management of PSD includes pharmacotherapy, psychotherapy, ${ }^{6}$ and electroconvulsive therapy (ECT), used especially in those with severe depressive illness.

\section{Pharmacological treatment}

Despite more than 100 years of studies of PSD, there are still several challenges regarding PSD pharmacotherapy, including determining its effectiveness. ${ }^{87}$ Pharmacotherapy may be particularly complicated in elderly PSD individuals, who often have high rates of medical comorbidity, concomitant 
polypharmacy, and more vulnerability to the adverse effects of antidepressants (ADs). It is important that the AD used should not only be effective in controlling mood disorders but also lack adverse effects on cognitive functions, which is particularly relevant to patients who have had strokes and more or less cognitive impairments ${ }^{46}$ (Table 4). There are many variables involved in pharmacotherapy of elderly patients, including pharmacokinetic changes associated with aging, drug interactions with other medications, preexisting illnesses, and adverse effects of the drugs on the elderly due to their increased vulnerability.

\section{$A D$ drugs}

ADs can be effective in most moderate and severe depressive disorders but are generally not indicated in mild forms because the balance of benefit and risk is not satisfactory in elderly stroke patients. Even when depression is properly diagnosed in elderly patients, they still may not receive the medication they require ${ }^{88}$ and because of possible severe side effects of ADs in elderly patients, more often the clinicians avoid prescribing such medications to them. ${ }^{88}$ Unfortunately, even when $\mathrm{AD}$ treatment is administered for an old patient, it is mostly in inadequate doses and for shorter durations than recommended. ${ }^{89}$

Until now, there is no evidence for using pharmacological or psychotherapeutic methods for PSD prevention after stroke, ${ }^{85,90,91}$ and a Cochrane meta-analysis of PSD treatment trials confirmed that there was no sufficient indication to suggest drug treatment specifically for the remission of PSD or its prevention. ${ }^{85,91}$ In a recent systematic review of trials on pharmacological therapy in PSD, Hackett et $\mathrm{al}^{92}$ reported that although ADs were able to reduce mood disorder symptoms, they had no clear effect on prevention or remission of depressive illness after stroke. However, a double-blind, placebo-controlled study performed by Robinson et $\mathrm{al}^{93}$ showed that escitalopram as preventive active drug, compared with placebo over the first year after stroke, decreased the frequency of PSD. However, the overall benefit when potential side effects and complications of active treatment are considered is still unclear.

Table 4 Criteria for ideal antidepressant choice in elderly patients

- Unaltered drug handling in old age

- Interaction free

- Safe in frail subjects with comorbid illnesses

- Simple dose regimen

- Well tolerated

- Rapid onset of antidepressant action

\section{The choice of ADs}

For the choice of ADs in PSD, the comparative information is quite limited, and none of them is specific to PSD. Selective serotonin reuptake inhibitors (SSRIs) are the first choice of PSD treatment in elderly patients due to their lower potential for drug interaction and side effects. Drug group, efficacy, and side effects of different medications are presented in Tables 5 and 6.

\section{Stimulant medications}

For many years, stimulant medications have been employed in stroke rehabilitation and in PSD, but large randomized clinical trials are still lacking. During 1950s, methylphenidate (MPH) was reported to be an effective treatment for geriatric depression, ${ }^{94}$ and case reports of Kaufman and his coworkers $^{80}$ also suggested the efficacy of MPH for PSD. Lingam et al conducted a retrospective study on the efficacy and side effects of MPH by systematically reviewing hospital charts of 25 depressed stroke patients, who were treated with MPH. ${ }^{95}$ The result of this study suggested a high degree of efficacy ( $80 \%$ improvement of depressive symptom) and a relatively low incidence of side effects. In a retrospective study, Lazarus et $\mathrm{al}^{96}$ reviewed hospital charts of older adults with stroke

Table 5 Antidepressants mostly used in late-life depression

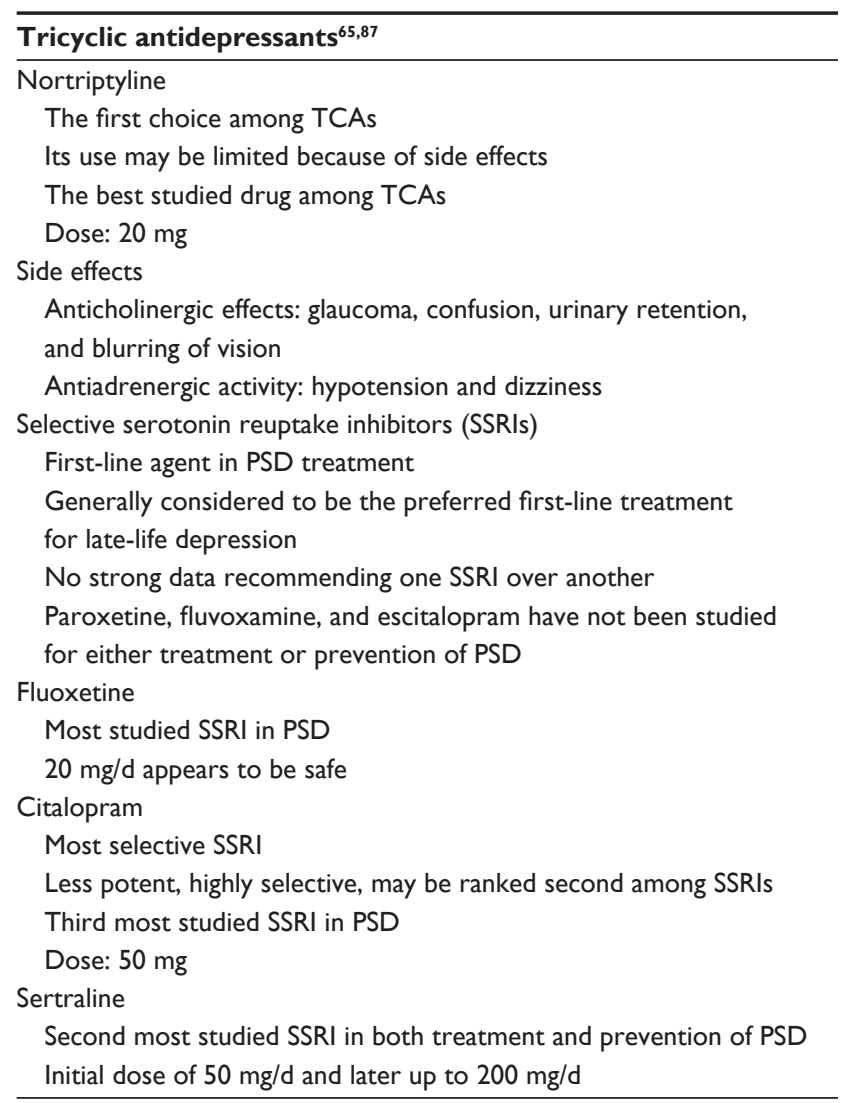

Abbreviations: TCAs, tricyclic antidepressants; PSD, poststroke depression. 
Table 6 Comparison of SSRIs with TCAs ${ }^{24,86,91}$

- Faster onset of action compared with TCAs

- At least as effective as the TCAs

- SSRIs have a more favorable safety profile

- SSRIs are generally not affected by age-related alterations in drug metabolism

- SSRIs can be administered in a simple, once-daily regimen, less confusing for elderly patients

- Improved tolerability of the SSRIs makes them a more appropriate choice for elderly patients

- SSRIs do not cause the anticholinergic effects like TCAs

- TCAs are potentially fatal in overdose (great concern in elderly PSD patients who are at increased risk of suicide)

- SSRIs are associated with a lower potential of drug interaction compared with TCAs

-A safer side-effect profile compared with TCAs

Abbreviations: SSRIs, selective serotonin reuptake inhibitors; TCAs, tricyclic antidepressants; PSD, poststroke depression.

and major depression. Among studied cases, 30 were treated with nortriptyline and 28 with MPH. Symptoms of depression resolved in $53 \%$ of MPH-treated patients and $43 \%$ of nortriptyline-treated patients, which showed no significant difference. ${ }^{96}$ However, a more significant difference was observed in response time. In MPH-treated patients, the mean response time to peak effect was 2.4 days compared with 27 days for nortriptyline-treated patients. Also, side effects were reported in $14 \%$ of MPH-treated patients and $30 \%$ of nortriptyline-treated patients, including delirium, requiring termination of nortriptyline therapy in 2 patients. ${ }^{96}$ They also prospectively studied MPH administration for elderly stroke patients (mean age, 73 years),${ }^{97}$ which was started at a dose of 2.5-5 $\mathrm{mg}$ in the morning and at noon, which was slowly increased to $40 \mathrm{mg} / \mathrm{d}$. Mean dosage used at about the 10th day was $17 \mathrm{mg} / \mathrm{d}$. Interestingly, over 3 weeks of therapy, $80 \%$ of patients showed a full or partial response based on Hamilton Depression Rating Scale. MPH was shown to be a safe and efficient therapy for elderly patients with PSD. Fast onset of action (usually within 3-10 days) and relatively few adverse effects of MPH may offer significant benefits over tricyclic ADs (TCAs), whose onset of action needs $2-4$ weeks. ${ }^{97}$ It can be concluded that specifically in conditions where patients' active participation in the recovery process is essential and issues like limitations in insurance coverage and subsequently shorter hospital stays, prescribing MPH would be best option.

In another prospective, randomized, double-blind, placebo-controlled study, Grade et a ${ }^{98}$ compared MPH and placebo among PSD patients. MPH was started at $5 \mathrm{mg}$ and increased gradually to $30 \mathrm{mg}(15 \mathrm{mg}$ at 8:00 $\mathrm{AM}$ and $15 \mathrm{mg}$ at 12:00 noon). After a 3-week treatment period with MPH (or placebo) in conjunction with physical therapy, the results confirmed that MPH is a safe and efficient adjunct therapy in the rehabilitation of acute stroke patients. MPH therapy has many benefits, including mood elevation, better motor functioning, and the ability to conduct regular daily activities without any considerable side effects.

\section{Course of drug treatment}

Based on the guidelines of the American College of Physicians, antidepressive drugs should be continued at least for 4 months after initial recovery and should be changed if no response has been seen after 6 weeks. ${ }^{99}$ AD treatment also should be continued for a minimum of 6 months in those patients with response to therapy. Later on, $\mathrm{AD}$ treatment can be slowly withdrawn, or in case of relapse, it can be continued for a longer duration. ${ }^{65,100}$ ADs should also be prescribed to patients with moderate to severe depression even before psychological interventions, and they should be continued for at least 4-6 weeks, at the doses recommended by the manufacturer ${ }^{64}$ (Figure 1).

\section{Nonpharmacological management}

Several reasons have been suggested in favor of nonpharmacological management, including the possibility of complications, which may occur when treating elderly depressed individuals due to adverse effects of the ADs, their inability to modify adverse environmental stressors, and a lack of social support factors, which often respond to a psychological approach. ${ }^{18}$ Nonpharmacological interventions in PSD have included psychotherapy, ECT, and transcranial magnetic stimulation. Psychological interventions are the preferred method of treatment for mild mood disorders ${ }^{64}$ and are reserved for those in whom ADs are either inappropriate or not tolerated. ${ }^{101}$ In most psychological treatments, a behavioral activation component is often involved, which treats the problem of activity limitation. Although some of these approaches mainly focus on the meaningfulness of the activity during the treatment, the possibility of targeting depression and intensifying and maintaining cognitions has also been practiced. ${ }^{24}$ Psychological treatments include behavioral therapy, cognitive behavioral therapy (CBT), problem-solving therapy, and life review therapy. ${ }^{102} \mathrm{Also}$, Watkins et al ${ }^{103}$ have recently shown that motivational interviewing is effective, leading to improved patients' mood 3 months after stroke. Unfortunately, there are some drawbacks for these interventions, including their costs in terms of staff time and expertise and their slow and delayed response, which requires several weeks before showing any clinical improvements. 


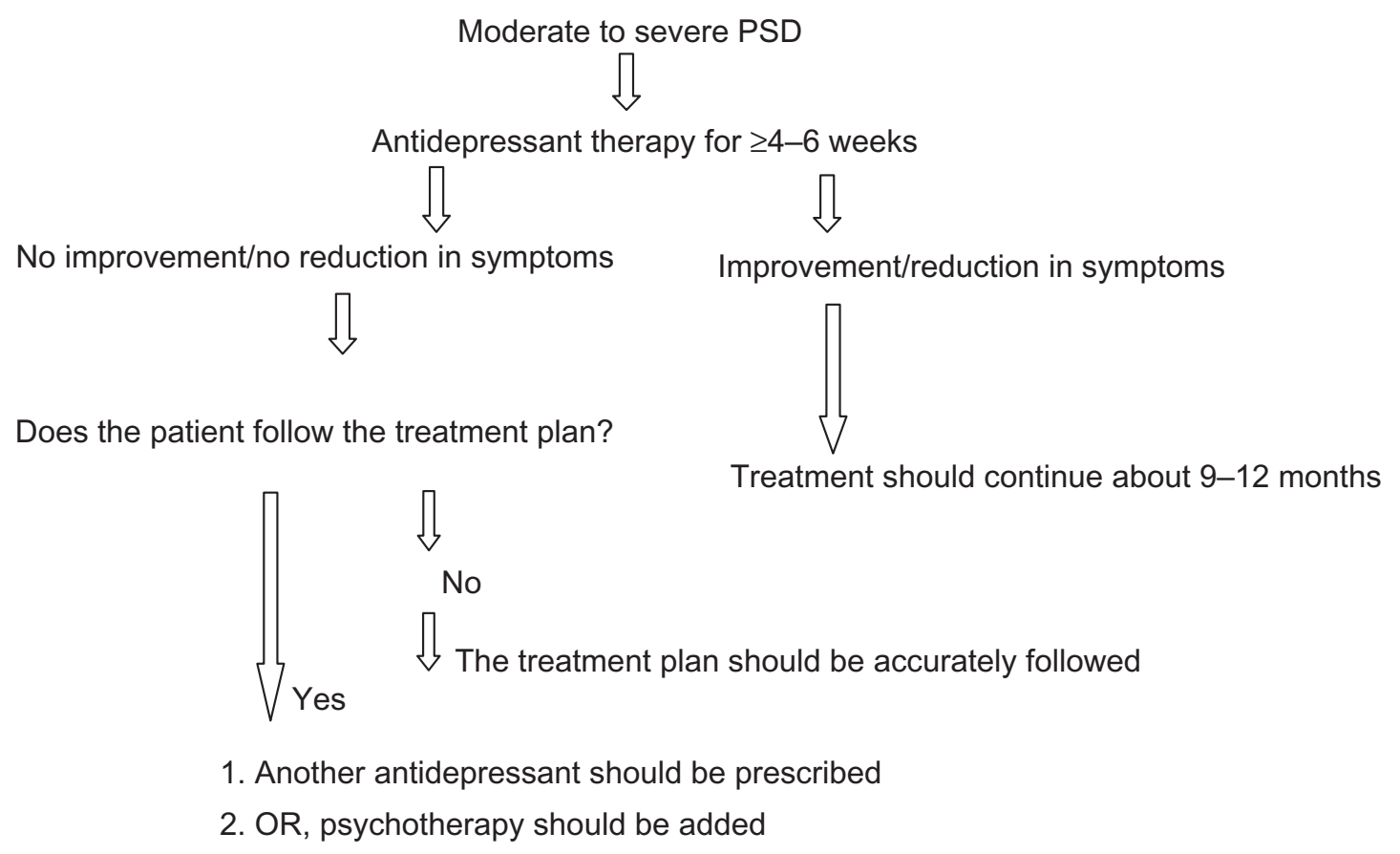

Figure I Flow chart of antidepressant therapy.

Abbreviation: PSD, poststroke depression.

\section{Cognitive behavioral therapy}

CBT has a very strong and positive effect on patients because it not only improves and builds confidence but also enhances the daily lifestyle of the patients through a range of activities. The treatment requires qualified health professionals to constantly evaluate the participants, making it easier to satisfy the diverse needs of the individuals. By this method, CBT is designed to challenge dysfunctional thoughts or beliefs that are associated with low mood and to collaboratively establish more functional thoughts or beliefs. ${ }^{66}$ However, patients with cognitive impairment and/or aphasia are not suited to this treatment form.

CBT is based on giving insights towards psychoeducation, collaborative empiricism, active problem solving, assessing the nature and quality of supports, and improvement of the adaptation to the new lifestyle after a stroke. ${ }^{104}$ Patients will find out how their thoughts may contribute to affective symptoms and feelings and how they can transform them. ${ }^{105}$

For individuals diagnosed with a range of chronic disabling physical conditions, such as stroke and PSD, a 12-week course of CBT, as advised and conducted by Kemp et al was shown effective. ${ }^{106}$

In general, approximately 6-8 regular sessions should be provided to patients over a period of 10-12 weeks, with most people experiencing an improvement in mood and/or a reduction in symptoms after 2 months of therapy. Response to therapy should be reviewed after 8 sessions. A therapy extension period of 6 months is considered necessary for a person who has multiple issues or severe comorbidity. ${ }^{64}$ Psychotherapy should be combined with ADs to reduce residual symptoms and the risk of relapse in patients with severe depression ${ }^{107}$ and in those with moderate or severe depression who refuse to take ADs. ${ }^{107}$ However, in a randomized controlled trial, Lincoln et $\mathrm{al}^{108}$ showed that CBT in the treatment of PSD was not effective, and they suggested that further evaluation with large sample size is needed to more clearly assess the role of CBT in PSD. Also in a Cochrane review for depression intervention after stroke, it was shown that psychotherapeutic intervention for PSD has failed to provide evidence for effectiveness. ${ }^{85}$

\section{Electroconvulsive therapy}

ECT should only be used to achieve rapid and short-term improvement of severe depressive symptoms after other treatments have proven ineffective. It is not recommended as a primary or maintenance therapy for PSD. ${ }^{109}$ It is used more often in older adults compared with any other age group. Its primary indication is severe depressive illness or when a disorder (or its symptoms) is considered potentially life threatening. ${ }^{64} \mathrm{~A}$ retrospective review of patients treated with ECT showed improvement in 95\% of PSD. ${ }^{110}$ Approximately $50 \%$ of patients had a prestroke history of major depression or alcoholism, and $85 \%$ already had received antidepressive medications to which they did not respond or were intolerant. 
According to the results obtained from 2 small samples of 14 and 20 PSD patients, ${ }^{111,112}$ approximately $40 \%$ of patients had a relapse of depressive symptoms after ECT in the short term ${ }^{111}$ and $20 \%$ developed medical complications. ${ }^{112} \mathrm{ECT}$ is therefore not a recommended therapy for depressed stroke patients, and adverse events such as cardiac complications, memory loss, and delirium suggest caution with the use of ECT for older PSD patients. ${ }^{64}$

\section{Key issues}

- Monitoring and assessing for depression are highly recommended after stroke, particularly for those having risk factors associated with PSD development, and delivering proper management, in the case of confirmed diagnosis.

- To improve recovery, facilitate rehabilitation, and decrease mortality, early recognition of PSD is required.

- Some factors, including older age, female sex, stroke severity, and functional dependence, further contribute to PSD development.

- There are a number of factors that make treatment more complicated in the elderly patient, including the high rate of comorbid disorders and often an increased sensitivity to possible side effects of medications.

- Evidence does not show any association between severity of PSD and side effect of stroke lesion.

- Frequency of depressive disorders in elderly patients is higher than the frequency of depressive disorders in age- and sexmatched controls.

- Despite serious mood disorders occurring after stroke, no reliable evidence-based clinical management method has existed so far.

- Treatment might be more demanding in elderly patients because of factors like the high rate of comorbid disorders and often an increased sensitivity to the side effects of medication.

- SSRIs have been found to be superior to TCAs in treatment of depression in old age.

- MPH appears to be a safe and effective treatment for elderly stroke patients with PSD.

- More advanced standard screening and diagnostic tools and more effective and safer treatments will help not only to treat this patient population effectively but also to decrease health care burden and costs.

\section{Disclosure}

The authors report no conflicts of interest in this work.

\section{References}

1. Hazzard W, Ettinger W Jr. Aging and atherosclerosis: changing considerations in cardiovascular disease prevention as the barrier to immortality is approached in old age. Am J Geriatr Cardiol. 1995; 4(4): $16-36$.
2. Sacco R, Adams R, Albers G, Alberts M, Benavente O, Furie K, et al; American Heart Association; American Stroke Association Council on Stroke; Council on Cardiovascular Radiology and Intervention; American Academy of Neurology. Guidelines for prevention of stroke in patients with ischemic stroke or transient ischemic attack: a statement for healthcare professionals from the American Heart Association/ American Stroke Association Council on Stroke: co-sponsored by the Council on Cardiovascular Radiology and Intervention: the American Academy of Neurology affirms the value of this guideline. Stroke. 2006;37(2):577-617.

3. The European Registers of Stroke (EROS) Investigators. Incidence of stroke in Europe at the beginning of the 21st century. Stroke. 2009;40(5):1557-1563.

4. Sanossian N, Ovbiagele B. Prevention and management of stroke in very elderly patients. Lancet Neurol. 2009;8(11):1031-1041.

5. Poynter B, Shuman M, Diaz-Granados N, Kapral M, Grace S, Stewart D. Sex differences in the prevalence of post-stroke depression: a systematic review. Psychosomatics. 2009;50(6):563-569.

6. Robinson RG. Neuropsychiatric consequences of stroke. Annu Rev Med. 1997;48(1):217-229.

7. Paolucci S, Antonucci G, Pratesi L, Traballesi M, Grasso M, Lubich S. Poststroke depression and its role in rehabilitation of inpatients. Arch Phys Med Rehabil. 1999;80(9):985-990.

8. van de Weg F, Kuik D, Lankhorst G. Post-stroke depression and functional outcome: a cohort study investigating the influence of depression on functional recovery from stroke. Clin Rehabil. 1999;13(3):268-272.

9. Pohjasvaara T, Vataja R, Leppävuori A, Kaste M, Erkinjuntti T. Depression is an independent predictor of poor long-term functional outcome post-stroke. Eur J Neurol. 2001;8(4):315-319.

10. Wade D, Legh-Smith J, Hewer R. Depressed mood after stroke. A community study of its frequency. Br J Psychiatry. 1987;151(2):200-205.

11. Parikh R, Eden D, Price T, Robinson R. The sensitivity and specificity of the Center for Epidemiologic Studies Depression Scale in screening for post-stroke depression. Int J Psychiatry Med. 1988;18(2): 169-181.

12. Starkstein S, Robinson R, Price T. Comparison of patients with and without poststroke major depression matched for size and location of lesion. Arch Gen Psychiatry. 1988;45(3):247-252.

13. Ensinck K, Schuurman A, van den Akker M, et al. Is there an increased risk of dying after depression? Am J Epidemiol. 2002;156(11):1043-1048.

14. Glassman A, Shapiro P. Depression and the course of coronary artery disease. Am J Psychiatry. 1998;155(1):4-11.

15. Berg A, Palomaki H, Lehtihalmes M, Lonnqvist J, Kaste M. Poststroke depression: an 18-month follow-up. Stroke. 2003;34(1):138-143.

16. Whyte E, Mulsant B, Vanderbuilt J, Dodge H, Ganguli M. Depression after stroke: a prospective epidemiological study. J Am Soc Geriatr Dent. 2004;52(5):774-778.

17. Provinciali L, Coccia M. Post-stroke and vascular depression: a critical review. Neurol Sci. 2002;22(6):417-428.

18. Gaete J, Bogousslavsky J. Post-stroke depression. Expert Rev Neurother. 2008;8(1):75-92.

19. Rao R. Cerebrovascular disease and late life depression: an age old association revisited. Int J Geriatr Psychiatry. 2000;15(5): 419-433.

20. Hackett M, Yapa C, Parag V, Anderson C. Frequency of depression after stroke. A systematic review of observational studies. Stroke. 2005;36(6):1330-1340.

21. House A, Dennis M, Mogridge L, Warlow C, Hawton K, Jones L. Mood disorders in the year after first stroke. Br J Psychiatry. 1991;158(1):83-92.

22. Andersen G, Vestergaard K, Riis J, Lauritzen L. Incidence of post-stroke depression during the first year in a large unselected stroke population determined using a valid standardized rating scale. Acta Psychiatr Scand. 2007;90(3):190-195.

23. Sonnenberg C, Beekman A, Deeg D, Tilburg W. Sex differences in late-life depression. Acta Psychiatr Scand. 2001;101(4):286-92. 
24. Fiske A, Wetherell J, Gatz M. Depression in older adults. Annu Rev Clin Psychol. 2009;5:363-389.

25. Murrell S, Himmelfarb S, Wright K. Prevalence of depression and its correlates in older adults. Am J Epidemiol. 1983;117(2):173-185.

26. Linden T, Blomstrand C, Skoog I. Depressive disorders after 20 months in elderly stroke patients: a case-control study. Stroke. 2007;38(6):1860-1863.

27. Robinson R. Vascular depression and poststroke depression: where do we go from here? Am J Geriatr Psychiatry. 2005;13(2):85-87.

28. Robinson R, Starr L, Lipsey J, Rao K, Price T. A two-year longitudinal study of post-stroke mood disorders: dynamic changes in associated variables over the first six months of follow-up. Stroke. 1984; 15(3):510-517.

29. Dieguez S, Staub F, Bruggimann L, Bogousslavsky J. Is poststroke depression a vascular depression? J Neurol Sci. 2004;226(1-2):53-58.

30. Carson A, MacHale S, Allen K, et al. Depression after stroke and lesion location: a systematic review. Lancet. 2000;356(9224):122-126.

31. Carod-Artal F. Are mood disorders a stroke risk factor? Stroke. 2007; 38(1):1-3.

32. Beblo T, Driessen M. No melancholia in poststroke depression? A phenomenologic comparison of primary and poststroke depression. J Geriatr Psychiatry Neurol. 2002;15(1):44-49.

33. Tateno A, Kimura M, Robinson R. Phenomenological characteristics of poststroke depression: early-versus late-onset. Am J Geriatr Psychiatry. 2002;10(5):575-582.

34. Robinson R, Bolduc P, Price T. Two-year longitudinal study of poststroke mood disorders: diagnosis and outcome at one and two years. Stroke. 1987;18(5):837-843.

35. Wilkinson P, Wolfe C, Warburton F, et al. A long-term follow-up of stroke patients. Stroke. 1997;28(3):507-512.

36. Sharpe M, Hawton K, House A, et al. Mood disorders in long-term survivors of stroke: associations with brain lesion location and volume. Psychol Med. 2009;20(04):815-828.

37. Astrom M, Adolfsson R, Asplund K. Major depression in stroke patients. A 3-year longitudinal study. Stroke. 1993;24(7):976-982.

38. Paradiso S, Vaidya J, Tranel D, Kosier T, Robinson R. Nondysphoric depression following stroke. J Neuropsychiatry Clin Neurosci. 2008;20(1):52-61.

39. Mast B. Cerebrovascular disease and late-life depression: a latentvariable analysis of depressive symptoms after stroke. Am J Geriatr Psychiatry. 2004;12(3):315-322.

40. Paradiso S, Ohkubo T, Robinson R. Vegetative and psychological symptoms associated with depressed mood over the first two years after stroke. Int J Psychiatry Med. 1997;27(2):137-157.

41. Fedoroff J, Starkstein S, Parikh R, Price T, Robinson R. Are depressive symptoms nonspecific in patients with acute stroke? Am J Psychiatry. 1991;148(9):1172-1176.

42. Desmond D, Remien R, Moroney J, Stern Y, Sano M, Williams J. Ischemic stroke and depression. J Int Neuropsychol Soc. 2003;9(03): 429-439.

43. Stein P, Sliwinski M, Gordon W, Hibbard M. Discriminative properties of somatic and nonsomatic symptoms for post stroke depression. Clin Neuropsychol. 1996;10(2):141-148.

44. Spalletta G, Bria P, Caltagirone C. Sensitivity of somatic symptoms in post-stroke depression (PSD). Int $J$ Geriatr Psychiatry. 2005;20(11):1103-1104.

45. Magni E, Frisoni G, Rozzini R, De Leo D, Trabucchi M. Depression and somatic symptoms in the elderly: the role of cognitive function. Int J Geriatr Psychiatry. 1998;11(6):517-522.

46. Gusev E, Bogolepova A. Depressive disorders in stroke patients. Neurosci Behav Physiol. 2009;39(7):639-643.

47. Gottfries C. Is there a difference between elderly and younger patients with regard to the symptomatology and aetiology of depression? Int Clin Psychopharmacol. 1998;13(5):S13-S18.

48. Carstensen L, Fung H, Charles S. Socioemotional selectivity theory and the regulation of emotion in the second half of life. Motiv Emot. 2003;27(2):103-123.

49. Shulman K. Conceptual problems in the assessment of depression in old age. Psychiatr J Univ Ott. 1989;14(2):364-366.
50. Christensen H, Jorm A, Mackinnon A, et al. Age differences in depression and anxiety symptoms: a structural equation modelling analysis of data from a general population sample. Psychol Med. 1999;29(02):325-339.

51. Aben I, Verhey F, Honig A, Lodder J, Lousberg R, Maes M. Research into the specificity of depression after stroke: a review on an unresolved issue. Prog Neuropsychopharmacol Biol Psychiatry. 2001;25(4): 671-690.

52. Ouimet M, Primeau F, Cole M. Psychosocial risk factors in poststroke depression: a systematic review. Can J Psychiatry. 2001;46(9): 819-828.

53. Hackett M, Anderson C. Predictors of depression after stroke: a systematic review of observational studies. Stroke. 2005;36(10):2296-2301.

54. Robinson R, Starr L, Kubos K, Price T. A two-year longitudinal study of post-stroke mood disorders: findings during the initial evaluation. Stroke. 1983;14(5):736-741.

55. Paradiso S, Robinson R. Gender differences in poststroke depression. J Neuropsychiatry Clin Neurosci. 1998;10(1):41-47.

56. Morris P, Robinson R, Raphael B, Samuels J, Molloy P. The relationship between risk factors for affective disorder and poststroke depression in hospitalised stroke patients. Aust $N Z J$ Psychiatry. 1992;26(2): $208-217$.

57. Strober LB, Arnett PA. Assessment of depression in three medically ill, elderly populations: Alzheimer's disease, Parkinson's disease, and stroke. Clin Neuropsychol. 2009;23(2):205-230.

58. Whyte E, Mulsant B. Post stroke depression: epidemiology, pathophysiology, and biological treatment. Biol Psychiatry. 2002;52(3): 253-264.

59. Schwartz J, Speed N, Brunberg J, Brewer T, Brown M, Greden J. Depression in stroke rehabilitation. Biol Psychiatry. 1993;33(10): 694-699.

60. Kotila M, Numminen H, Waltimo O, Kaste M. Depression after stroke: results of the FINNSTROKE Study. Stroke. 1998;29(2):368-372.

61. Andersen G, Vestergaard K, Ingemann-Nielsen M, Lauritzen L. Risk factors for post-stroke depression. Acta Psychiatr Scand. 2007;92(3):193-198.

62. Gabaldón L, Fuentes B, Frank-García A, Díez-Tejedor E. Poststroke depression: importance of its detection and treatment. Cerebrovasc Dis. 2007;24(1):181-188.

63. Gordon W, Hibbard M. Poststroke depression: an examination of the literature. Arch Phys Med Rehabil. 1997;78(6):658-663.

64. Hackett M, Anderson C. Treatment options for post-stroke depression in the elderly. Aging Health. 2005;1(1):95-105.

65. Turner-Stokes L, Hassan N. Depression after stroke: a review of the evidence base to inform the development of an integrated care pathway. Part I: Diagnosis, frequency and impact. Clin Rehabil. 2002;16(3):231-247.

66. Laidlaw K. Post-stroke depression and CBT with older people. In: Dolores G-T, Ann MS, Lary WT, editors. Handbook of Behavioral and Cognitive Therapies with Older Adults. New York: Springer; 2007:233-248.

67. Gupta A, Pansari K, Shetty H. Post-stroke depression. Int J Clin Pract. 2002;56(7):531-537.

68. Agrell B, Dehlin O. Comparison of six depression rating scales in geriatric stroke patients. Stroke. 1989;20(9):1190-1194.

69. Sheikh J, Yesavage J. Geriatric Depression Scale (GDS): recent evidence and development of a shorter version. Clin Gerontol. 1986;5(1-2): 165-173.

70. Carod-Artal F, Ferreira Coral L, Trizotto D, Menezes Moreira C. Poststroke depression: prevalence and determinants in Brazilian stroke patients. Cerebrovasc Dis. 2009;28(2):157-165.

71. Tang W, Ungvari G, Chiu H, Sze K, Yu A, Leung T. Screening post-stroke depression in Chinese older adults using the hospital anxiety and depression scale. Aging Ment Health. 2004;8(5):397-399.

72. Johnson G, Burvill P, Anderson C, Jamrozik K, Stewart-Wynne E, Chakera T. Screening instruments for depression and anxiety following stroke: experience in the Perth community stroke study. Acta Psychiatr Scand. 2007;91(4):252-257. 
73. Incalzi R, Cesari M, Pedone $\mathrm{C}$, Carbonin P. Construct validity of the 15-item geriatric depression scale in older medical inpatients. J Geriatr Psychiatry Neurol. 2003;16(1):23-28.

74. Diamond P, Holroyd S, Macciocchi S, Felsenthal G. Prevalence of depression and outcome on the geriatric rehabilitation unit. Am J Phys Med Rehabil. 1995;74(3):214-217.

75. Stiles P, McGarrahan J. The Geriatric Depression Scale: a comprehensive review. J Clin Geropsychol. 1998;4(2):89-110.

76. Tang W, Chan S, Chiu H, et al. Can the Geriatric Depression Scale detect poststroke depression in Chinese elderly? J Affect Disord. 2004; 81(2):153-156.

77. Healey A, Kneebone I, Carroll M, Anderson S. A preliminary investigation of the reliability and validity of the Brief Assessment Schedule Depression Cards and the Beck Depression Inventory-Fast Screen to screen for depression in older stroke survivors. International Journal of Geriatric Psychiatry. 2008;23(5):531-536.

78. Adshead F, Cody D, Pitt B. BASDEC: a novel screening instrument for depression in elderly medical inpatients. Br Med J. 1992; 305(6850):397.

79. Yohannes A, Baldwin R, Connolly M. Depression and anxiety in elderly outpatients with chronic obstructive pulmonary disease: prevalence, and validation of the BASDEC screening questionnaire. Int J Geriatr Psychiatry. 2001;15(12):1090-1096.

80. McCrea D, Arnold E, Marchevsky D, Kaufman B. The prevalence of depression in geriatric medical outpatients. Age Ageing. 1994;23(6): 465-467.

81. Carl C. Bell. Diagnostic and Statistical Manual of MentalDdisorders. 4th ed. Washington, DC: American Psychiatric Association; 1994

82. Rigler S. Management of poststroke depression in older people. Clin Geriatr Med. 1999;15(4):765-783.

83. Rabins P. Barriers to diagnosis and treatment of depression in elderly patients. Am J Geriatr Psychiatry. 1996;4:79-83.

84. Schubert D, Taylor C, Lee S, Mentari A, Tamaklo W. Detection of depression in the stroke patient. Psychosomatics. 1992;33(3):290-294.

85. Hackett M, Anderson C, House A, Xia J. Interventions for treating depression after stroke. Stroke. 2009;40(7):e487-e488.

86. Alexopoulos G, Buckwalter K, Olin J, Martinez R, Wainscott C, Krishnan K. Comorbidity of late life depression: an opportunity for research on mechanisms and treatment. Biol Psychiatry. 2002;52(6): $543-558$

87. Tharwani H, Yerramsetty P, Mannelli P, Patkar A, Masand P. Recent advances in poststroke depression. Curr Psychiatry Rep. 2007;9(3): 225-231.

88. Katona C. Managing depression and anxiety in the elderly patient. Eur Neuropsychopharmacol. 2000;10:S427-S432.

89. Peveler R CA, Rodin G. Depression in medical patients. BMJ. 2002; 325(7356):149-152.

90. Bhogal S, Teasell R, Foley N, Speechley M. Heterocyclics and selective serotonin reuptake inhibitors in the treatment and prevention of poststroke depression. J Am Geriatr Soc. 2005;53(6): 1051-1057.

91. Anderson C, Hackett $\mathrm{M}$, House A. Interventions for preventing depression after stroke. Cochrane Database Syst Rev. 2004;(2):CD003689.

92. Hackett M, Anderson C, House A. Management of depression after stroke: a systematic review of pharmacological therapies. Stroke. 2005;36(5):1092-1097.
93. Robinson R, Jorge R, Moser D, et al. Escitalopram and problemsolving therapy for prevention of poststroke depression: a randomized controlled trial. JAMA. 2008;299(20):2391-2400.

94. Cao C, Patel V, Reddy C, Hovakimyan N, Lavretsky E, Wise K, editors. Are phase and time-delay margin always adversely affected by high gains? Available from: http://www.engr.uconn.edu/ ccao/caopaper/ CaoAIAA06Phase.pdf Accessed July 15, 2010.

95. Lingam VR LL, Groves L, Oh SH. Methylphenidate in treating poststroke depression. Journal of Clinical Psychiatry. 1988;49(4):151-153.

96. Lazarus L, Moberg P, Langsley P, Lingam V. Methylphenidate and nortriptyline in the treatment of poststroke depression: a retrospective comparison. Arch Phys Med Rehabil. 1994;75(4):403-406.

97. Lazarus L, Winemiller D, Lingam V, et al. Efficacy and side effects of methylphenidate for poststroke depression. J Clin Psychiatry. 1992;53(12):447-449.

98. Grade C, Redford B, Chrostowski J, Toussaint L, Blackwell B. Methylphenidate in early poststroke recovery: a double-blind, placebocontrolled study. Arch Phys Med Rehabil. 1998;79(9):1047-1050.

99. Snow V, Lascher S, Mottur-Pilson C. Pharmacologic treatment of acute major depression and dysthymia: clinical guideline, Part 1. Ann Intern Med. 2000;132(9):738-742.

100. Williams LS. Depression and stroke: cause or consequence? Semin Neurol. 2005;25(4):396-409.

101. Paolucci S. Epidemiology and treatment of post-stroke depression. Neuropsychiatr Dis Treat. 2008;4(1):145-154.

102. Scogin F, Welsh D, Hanson A, Stump J, Coates A. Evidence-based psychotherapies for depression in older adults. Clin Psychol: Sci Pract. 2006;12(3):222-237.

103. Watkins C, Auton M, Deans C, et al. Motivational interviewing early after acute stroke: a randomized, controlled trial. Stroke. 2007;38(3):1004-1009.

104. Gallagher-Thompson D, Steffen A, Thompson L, Vandenbulcke M. Handbook of Behavioral and Cognitive Therapies with Older Adults. New York: Springer; 2008.

105. Gebretsadik M, Jayaprabhu S, Grossberg G. Mood disorders in the elderly. Med Clin North Am. 2006;90(5):789-805.

106. Kemp B, Corgiat M, Gill C. Effects of brief cognitive-behavioral group psychotherapy on older persons with and without disabling illness Behave Health Ageing. 1992;2:21-28.

107. Australian R, Depression N. Australian and New Zealand clinical practice guidelines for the treatment of depression. Aust N ZJ Psychiatry. 2004;38(6):389-407.

108. Lincoln N, Flannaghan T. Cognitive behavioral psychotherapy for depression following stroke: a randomized controlled trial. Stroke. 2003;34(1):111-115.

109. Anderson C, Skegg P, Wilson R, Hackett M, Snelling J, Grover A Use of electroconvulsive therapy (ECT) in New Zealand: a review of efficacy, safety and regulatory controls. Wellington, New Zealand: Ministry of Health; 2005.

110. Kelly K, Zisselman M. Update on electroconvulsive therapy (ECT) in older adults. J Am Geriatr Soc. 2000;48(5):560-566.

111. Murray G, Shea V, Conn D. Electroconvulsive therapy for poststroke depression. J Clin Psychiatry. 1986;47(5):258.

112. Currier M, Murray G, Welch C. Electroconvulsive therapy for poststroke depressed geriatric patients. J Neuropsychiatry Clin Neurosci. 1992;4(2):140-144.
Neuropsychiatric Disease and Treatment

\section{Publish your work in this journal}

Neuropsychiatric Disease and Treatment is an international, peerreviewed journal of clinical therapeutics and pharmacology focusing on concise rapid reporting of clinical or pre-clinical studies on a range of neuropsychiatric and neurological disorders. This journal is indexed on PubMed Central, the 'PsycINFO' database and CAS, and is the official

\section{Dovepress}

journal of The International Neuropsychiatric Association (INA). The manuscript management system is completely online and includes a very quick and fair peer-review system, which is all easy to use. Visit http://www.dovepress.com/testimonials.php to read real quotes from published authors. 